\title{
RELAÇÕES RACIAIS NO FACEBOOK: ANÁLISE DE COMENTÁRIOS ACERCA DE CONTEÚDOS RACIAIS DIGITAIS
}

\author{
Sheyla Fernandes ${ }^{1}$, Marcikele Nascimento ${ }^{2}$, Alanda Pereira ${ }^{3}$, Erika Melo ${ }^{4}$ e Kathleen \\ Carlos $^{5}$

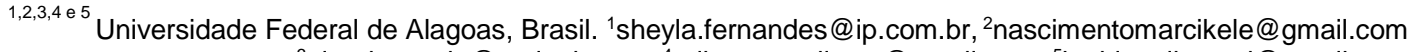 \\ 3alanda-maria@outlook.com, ${ }^{4}$ erikamanuellasm@gmail.com, ${ }^{5}$ kathleenlimapsi@gmail.com
}

\begin{abstract}
Resumo. Introdução: No Brasil, o racismo é visto como inexistente, tendo em vista que se nega qualquer manifestação desse comportamento ou é atrelado à conduta do outro. Contudo, essa negação não apaga sua incidência. Objetivos: Partindo dessa evidência, que pode ser reportada no desenvolvimento das relações físicas e virtuais, esta pesquisa tem por objetivo conhecer as crenças raciais no Facebook. Métodos: Os dados para realização deste estudo foram coletados a partir do descritor "Racismo", buscado em páginas e grupos abertos no site Facebook (http://facebook.com.br/). Tais comentários foram transformados em um corpus textual analisado a partir do software Iramuteq. Resultados: A Classificação Hierárquica Descendente - CHD estruturou os comentários em 4 classes: Classe 1 "ideologia de branqueamento", (38,07\% das UCEs); Classe 2 "representatividade negra", (15,34\% das UCEs); Classe 3 "o mito da democracia racial", $(28,41 \%$ das UCEs) e Classe 4 "inferiorização social", (18,18 \% das UCEs). Conclusões: Os resultados da análise mostram como as crenças raciais são expostas no Facebook, reproduzindo manifestações ofensivas, que corroboram com o racismo que acontece no contexto físico.
\end{abstract}

Palavras-chave: Racismo; Crenças; Facebook.

\section{RACIAL RELATION ON FACEBOOK: ANALYSIS OF COMMENTS ABOUT DIGITAL RACIAL CONTENT}

\begin{abstract}
Introduction In Brazil, racism is seen as non-existent, considering that any manifestation of this behavior is denied or linked to the conduct of another. However, this denial is not caused by its incidence. Goals Based on this evidence, which can be reported in the development of affective and virtual relationships, this research aims to understand racial beliefs on Facebook. Methods The data for carrying out this study were collected from the descriptor "Racism", searched on pages and groups open on the Facebook site (http://facebook.com.br/). Such comments were transformed into a corpus of textual analysis using the Iramuteq software. Results The Descending Hierarchical Classification - CHD structured the comments into 4 classes: Class 1 "whitening ideology" (38.07\% of the ECUs); Class 2 "black representation", (15.34\% of the ECUs); Class 3 "myth of racial democracy", (28.41\% of UCEs) and Class 4 "social inferiority", (18.18\% of UCEs). Conclusions The results of the analysis show how racial causes are exposed on Facebook, reproducing offensive manifestations, which corroborate the racism that happens in the physical context.
\end{abstract}

Keywords: Racism; Beliefs; Facebook.

\section{INTRODUÇÃO - RACISMO: DEFINIÇÕES E FORMAS DE EXPRESSÃO}

Em 2019, o jogo do Brasil contra a França na Copa do Mundo de Futebol Feminino virou notícia em todas as mídias, sobretudo, nas mídias digitais. Comentários racistas direcionados a uma jogadora francesa negra sobre seu cabelo não alisado impeliu as pessoas a debaterem sobre ela não estar utilizando seu salário "exorbitante" com 
adequação. A reportagem publicada pelo portal de notícias uol acerca da atitude preconceituosa de telespectadores brasileiros, demonstra a presença de um racismo cordial à espreita de uma oportunidade para se apresentar (Silva, 2019). O racismo cordial é uma tipologia de racismo caracterizada por uma falsa cordialidade amparada na ocultação de atitudes e comportamentos discriminatórios contra indivíduos não brancos (mestiços e negros) (Pires, 2010).

Allport (1954) define o preconceito como uma atitude hostil direcionada a uma pessoa pertencente a um determinado grupo. Nesse sentido, a pessoa em questão, pelo simples fato de estar inserida no grupo alvo de preconceito, seria uma extensão das qualidades negativas atribuídas ao grupo.

O preconceito e suas múltiplas formas de expressão são apreendidos enquanto fenômenos sociais marcados pelas relações intergrupais e pelos respectivos processos políticos que as instauram. Sua exteriorização é moldada, portanto, pelo curso histórico e contexto social no qual o indivíduo está inserido. Os valores individuais e as atitudes internalizadas são provenientes do contato social, refletidos em nossas relações sociais (Fernandes, 2011; Myers, 2014). Assim, as formas de expressar o preconceito são elaboradas em virtude das normas sociais que limitam a expressão do preconceito com a finalidade de amparar uma certa perspectiva falsa de igualdade racial (Guimarães, 2004).

No entanto, a historicidade das relações raciais é demarcada pela condição de inferiorização dos negros desde o período de escravidão, o que revela com clareza a desigualdade social (Cruz, 2017). Um fenômeno que eclode paralelo ao racismo é o branqueamento das pessoas negras. Segundo Carone (2017), o branqueamento pode ser entendido de duas formas, como a miscigenação da população, gerando grupos menos enegrecidos, e como uma pressão cultural exercida pelas pessoas não negras para que os negros neguem a si mesmos no que se refere a traços, cultura e demais características.

Nesse contexto, investigar elementos das relações raciais no Brasil implica considerar a singularidade deste fenômeno no contexto brasileiro e suas formas específicas de expressão na contemporaneidade. Resulta, portanto, inserir na discussão as crenças que ancoram os discursos racistas em um povo cuja característica central é a miscigenação. 
Um lócus que parece favorecer a expressão aberta de crenças vem tomando cada vez mais espaço na vidas das pessoas, trata-se das redes sociais. Portanto, o interesse dessa investigação toma como campo de coleta de informações o Facebook.

\subsection{Facebook e relações raciais}

Os sites de redes sociais constituem a crescente estratégia de comunicação da contemporaneidade. Todavia, a livre circulação de informações pode ser utilizada enquanto estratégia de humilhação, opressão e desvalorização da identidade de grupos minoritários (Martins, 2019). Assim, "a instantaneidade com que comentários positivos e negativos chegam até a plataforma desafia a quem administra as páginas do Facebook e de outras mídias sociais" (Stein, Nodari \& Salvagni, 2018, p.44). A falta de controle do que é veiculado demonstra que este é um campo fértil para a exteriorização de atitudes preconceituosas.

Em relação aos sites de rede social, o Facebook domina o panorama social global, a plataforma atingiu quase 2,17 bilhões de usuários no início de 2018 (Kemp, 2018). Partindo do pressuposto de que o racismo ainda predomina na contemporaneidade, no desenvolvimento das relações, é de fundamental importância investigar como se comportam as pessoas diante do ambiente virtual, mediante o compartilhamento de ideias e discussões na rede social em questão. Nessa perspectiva, compreendendo a influência do construto na construção das relações raciais brasileiras, o presente estudo objetivou conhecer as crenças raciais no Facebook. A análise realizada ocorreu a partir de um diálogo com o modelo de racismo cordial apresentado por Turra e Venturi (1995).

Turra e Venturi (1995) apresentam o racismo cordial enquanto um modelo de racismo específico da sociedade brasileira onde as atitudes preconceituosas são sustentadas pela demonstração de uma falsa cordialidade. A partir do estudo realizado, os autores demonstraram a existência de uma situação enigmática referente ao racismo no país: falta de distinção entre povos de etnias diferentes, a presença comprovada do preconceito de cor, a negação de atitudes preconceituosas, e a indiferença a experiências relacionadas com a discriminação racial.

A temática do racismo apresenta diferentes faces e, apesar dos notórios avanços acerca das discussões referentes ao preconceito étnico e racial, ainda existe uma série de aspectos provenientes deste que limitam as relações contemporâneas. As inúmeras formas de exteriorização de opiniões preconceituosas demonstram que o branqueamento e a 
idealização de uma igualdade racial brasileira vêm sendo discutidas desde o século $X X$, e ainda são predominantes na atualidade. Além disso, são estratégias de manutenção do processo de inclusão-exclusiva do negro na sociedade brasileira (Silva, 2017).

\section{METODOLOGIA}

Os dados utilizados na análise foram coletados pelas autoras durante o processo de investigação. Inicialmente realizou-se uma busca no site Facebook (http://facebook.com.br/), buscando selecionar grupos e páginas com discussões referentes ao preconceito, racismo e a negritude. Para tanto, utilizou-se na barra de pesquisa da rede social o descritor "Racismo". As páginas e os grupos foram selecionados considerando-se os seguintes critérios: (1) trabalhar assuntos relativos ao tópico; (2) serem abertos; (3) apresentarem um número mínimo de um mil seguidores/membros.

Posteriormente, selecionou-se os comentários das 5 postagens mais visualizadas e ou curtidas no período de busca que foi entre $1^{\circ}$ de outubro a 31 de dezembro de 2017 . Após essa etapa os comentários foram colhidos e gerou-se um corpus textual para ser analisado com auxílio do software Iramuteq. Na elaboração do corpus foi mantido o anonimato de todos os indivíduos que comentaram as publicações.

Tendo os dados em mãos, estes foram transcritos com auxílio do OpenOffice Writer. O OpenOffice Writer é um aplicativo livre e gratuito que apresenta uma variabilidade de instrumentos de programação e é originalmente voltado para a edição de textos, sendo uma importante ferramenta para a realização de tarefas simples ou mais complexas (Afonso, 2010).

Em seguida, os dados foram revisados, eliminando todos aqueles que não envolviam a temática Racismo. Com o corpus devidamente elaborado, pode-se realizar o processamento com o Iramuteq (Interface de $\mathrm{R}$ pour les Analyses Multidimensionnelles de Textes et de Questionnaires; Ratinaud, 2009), o programa se encontra na plataforma R (R Core Team, 2012) na linguagem de programação python (www.python.org) e possui diversas formas de análise. Nesta pesquisa, considerou-se a análise de Classificação Hierárquica Descendente (CHD). O corpus apresentou, 221 segmentos de texto (ST), 7967 palavras (número de ocorrências), onde 1606 aparecem somente uma vez. Após a organização do corpus, foi salvo no bloco de notas na função UTF-8 para poder ser analisado pelo Iramuteq (Ratinaud, 2009). 
Foi realizada uma Classificação Hierárquica Descendente (CHD), que possibilita a classificação a partir dos segmentos de textos (ST) que são divididos de acordo com a apresentação da frequência das formas reduzidas. Em decorrência do cruzamento dos ST, o método de CHD possibilita apresentação de uma classificação estável e definitiva. Tais segmentos possuem semelhanças entre si e diferenças entre as ST das outras classes (Salviati, 2017). Além disso, para que haja a classificação são consideradas as frequências das palavras e o qui-quadrado $\left(\mathrm{X}^{2}\right)$. Com intuito de tornar a análise dos dados mais ampla e completa, considerou-se todo o conteúdo do modo automático (default) do software.

O dendograma da CHD demonstra as relações existentes entre as classes, permitindo, assim a descrição de cada classe a partir de seu vocabulário característico e pelas suas palavras correspondentes, possibilitando a criação de classes de unidades de contexto elementares (UCEs) que são construídas a partir dos elementos prevalentes nos corpus textuais . Também existe a possibilidade de uma apresentação dos resultados através de uma análise fatorial de correspondência realizada por meio da CHD. Após a seleção das classes, o programa calcula e apresenta os ST mais importantes de cada classe possibilitando a interpretação do vocabulário específico de cada classe (Camargo \& Justo, 2013).

\section{RESULTADOS}

A CHD apresentou a divisão do conteúdo em 4 classes, tendo aproveitado 176 ST dos 221 (79,64\%) (Figura 1). As análises do tipo CHD demandam uma retenção mínima de $75 \%$ dos segmentos de texto para serem consideradas úteis à classificação do conteúdo textual. Caso a retenção obtida seja inferior a esse valor, a classificação é considerada parcial e a análise torna-se inadequada aos dados coletados (Camargo \& Justo, 2016). 


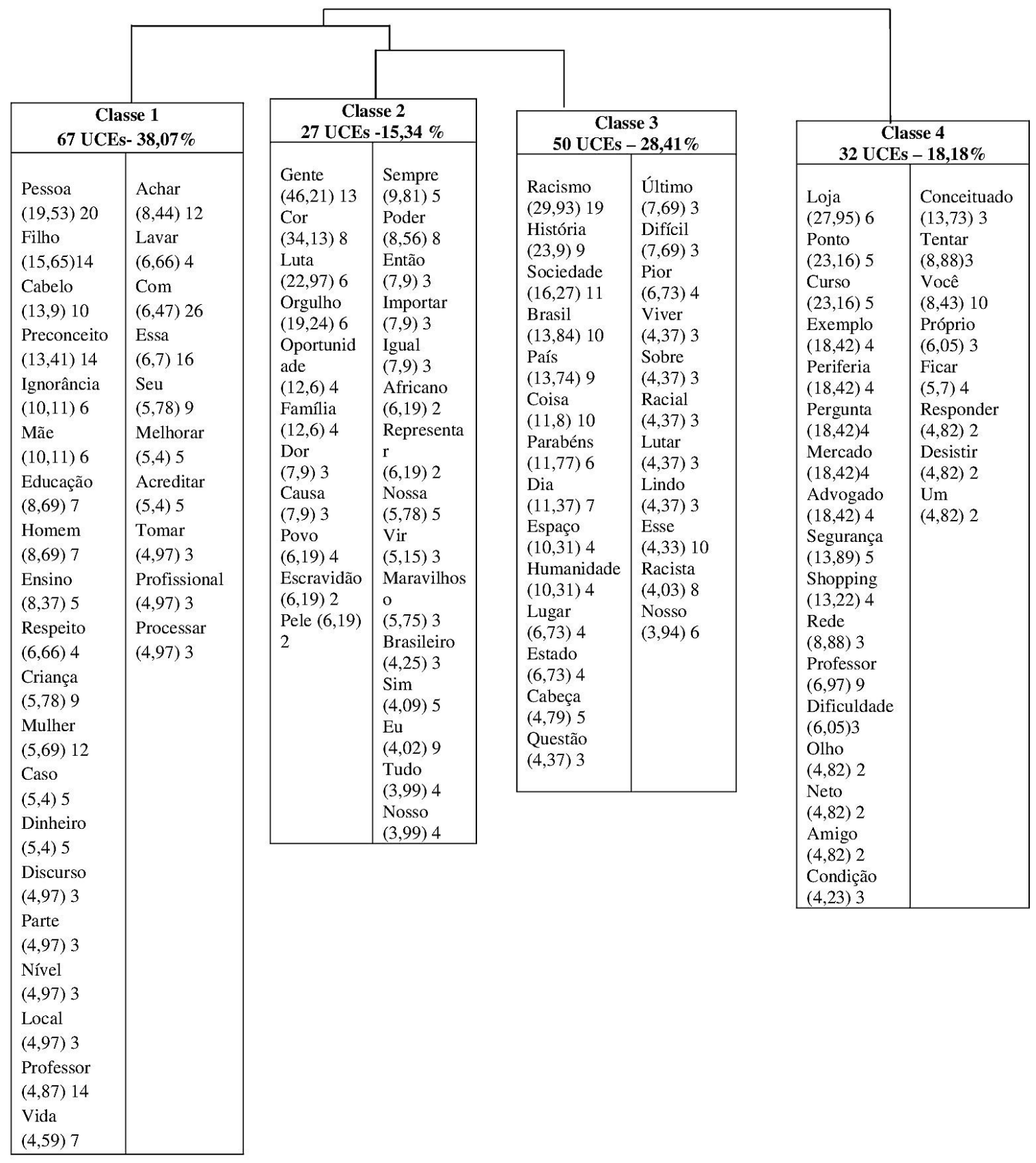

Figura 1. Dendograma do corpus sobre racismo.

O dendograma do corpus apresenta as palavras que emergiram em cada uma das classes junto ao qui-quadrado $\left(x^{2}\right)$ e sua frequência. A classe 1, nomeada "ideologia do branqueamento", apresentou um aproveitamento de 38,07\% das UCEs. Esta classe retrata comentários relacionados a forma como os indivíduos apresentam o sentimento de pertença frente a uma outra raça, a partir de uma demanda de branquitude da pele negra. Observam- 
se aspectos relacionados ao reconhecimento da inferioridade de características provenientes da população negra e uma expressiva demonstração dessa atitude de hostilidade. São constantes os relatos de indivíduos que convivem com o racismo por estarem afetivamente próximos a pessoas negras. Esta classe pode ser ilustrada através de comentários como "a criança chegou... chorando porque ouviu que seu cabelo não foi lavado por ser duro", "convivo com preconceito desde sempre porque me casei com homem negro".

A segunda classe foi nomeada "representatividade negra" e abarcou 15,34\% das UCEs. Esta classe explicita a importância das conquistas dos atores sociais enquanto ferramenta de coibição do preconceito contra negros. Tal elemento de valorização sugere um contraponto à lógica da inclusão-exclusão sustentada pela ideologia do branqueamento demonstrada na classe 1. Ressalta, portanto, uma crescente reconfiguração na demarcação do lugar do negro na sociedade, uma vez que a sua inserção em espaços que outrora eram predominantemente brancos e o reconhecimento das conquistas historicamente alcançadas encaminham para o possível surgimento do sentimento de pertencimento e representatividade. Assim, torna-se possível apreender a influência direta do reconhecimento de avanços individuais e coletivos para o sentimento de pertença grupal. É possível perceber a importância da representatividade em trechos como: "vai ter quilombola na universidade e formado sim", "sinto tanto orgulho das mulheres pretas guerreiras que me precederam e abriram caminho para que eu pudesse me construir", "gente que continua lutando e gente que luta e lutou apoiando de todas as maneiras possíveis a causa negra".

A classe 3 foi nomeada como "desigualdade racial" e apresentou um aproveitamento de $28,41 \%$ das UCEs. Esta classe retrata comentários relacionados com a falta de harmonia nas relações raciais existentes no país. É possível reconhecer aspectos constituintes de uma relação eminentemente desigual que subsidiada pela perspectiva presente no imaginário social se perpetua sem um movimento de reflexão. São recorrentes os comentários acerca de comportamentos racistas que resultam em consequências devastadoras na vida de indivíduos vítimas de tais comentários. A classe em questão demonstra que o brasileiro circunscrito na negação da existência do racismo, diante da possibilidade de sua existência atribuí o comportamento racista a um outro, a fim de se defender da imagem de opressor, o sujeito quase sempre se afasta da auto-classificação de preconceituoso. 
Seu discurso demonstra um movimento de falseamento de uma harmonia inter-racial, falsificação esta que oprime a vítima que não pode reclamar de um fenômeno "inexistente". Esta classe pode ser exemplificada a partir de comentários como, "racismo é um dos assuntos que menos importa para mim", "aquela velha história de não sou racista, mas sim somos, em diversos momentos, sem xingar, sem ofender, mas com pequenos gestos", "o racismo continua impregnado em almas e mentes pequenas", "a sociedade igualitária não existe...o negro sempre foi o cidadão de segunda classe".

Por fim, a classe 4, nomeada "inferiorização dos negros" (18,8 \% das UCEs), uma vez que evidencia na atualidade uma expressão do racismo culturalmente sustentada através do discurso da diminuição do outro. Através deste discurso legitima-se, portanto, a exclusão social em detrimento da negação da inclusão, em que frequentemente reduz-se oportunidades de inserção social para a população negra. Esta classe apresenta a falta de oportunidades que os negros enfrentam cotidianamente. Dificuldades enfrentadas ao ingressar no ensino superior, no mercado de trabalho e até mesmo na construção de relacionamentos, exemplificam algumas problemáticas sociais atreladas ao racismo. Podemos visualizar exemplos de trechos que descrevem esta classe, "Na maioria das lojas não há nem um negro atendendo e isso não é falta de capacidade, posso te garantir, é falta de oportunidade, posso te garantir", "Para você pontuar que ele é advogado conceituado talvez seja porque ele ainda é exceção...se fosse regra não teria porque mencionar isso".

\section{DISCUSSÃO}

Diante dos resultados apresentados, é possível reconhecer na atualidade a demonstração de uma explicitação de aspectos constituintes do racismo cordial apresentado por Turra e Venturi (1995). De acordo com os autores, o fenômeno é característico do Brasil e demonstra elementos constituintes das relações raciais brasileiras. O termo cordial foi escolhido "em virtude da cordialidade com que se nega ser racista neste país" (Fernandes, 2011, p.75). Em relação a esta cordialidade e a caracterização brasileira do racismo, os resultados das análises textuais do atual estudo possibilitaram elencar 4 considerações principais: a) há uma ideologia de branqueamento que visa atenuar a negritude; b) é notável uma representatividade negra crescente que milita em prol de seus direitos; c) não se nega a existência da desigualdade racial e d) a inferiorização dos negros aparece como característica das relações raciais brasileiras. 
A partir da análise do software, as classes são apresentadas separadamente, contudo, na prática, tais atitudes racistas possuem uma ligação e uma continuidade que permitem o estudo do comportamento racista na sociedade brasileira, a partir de sua reprodução em uma rede social, tal como ocorre nos contextos das relações sociais cotidianas. Como apresentado pelo conteúdo textual da classe 3, a discussão sobre Racismo na atualidade é, muitas vezes, desqualificada em virtude de discursos sustentados por um ideal de que o problema do racismo é sempre do outro. Poucos admitem ser racistas em um país que possui uma população miscigenada (Bernardino, 2002).

As atitudes racistas perpassam o campo físico se proliferando nas redes sociais, que possuem um maior alcance na propagação de ideias e discussões, como o Facebook. A violência "discreta" que limita o acesso a oportunidades, constrange a vítima e posiciona o opressor enquanto alienado às consequências de suas práticas, viraliza nos sites de redes sociais e é tomada pelos internautas enquanto uma simples brincadeira.

No Brasil, as atitudes preconceituosas ou racistas contra as pessoas negras ocorrem praticamente todos os dias, fato demonstrado pelos comentários de cunho racista direcionados à jogadora francesa que participou da copa feminina de futebol (Silva, 2019). Nesse sentido, a classe 1 aponta para a permanência da idealização do branqueamento no imaginário social brasileiro, esta idealização é normativa na medida em que seleciona as características padrão do indivíduo branco em oposição à desqualificação de características provenientes da população negra (Lima \& Vala, 2004). Por ser normativa, abre caminho portanto, para a valorização da negação da historicidade negra no país.

Além disso, vale lembrar que a tentativa de negação do racismo no Brasil também conduz a um processo de tentativa de apagamento das características negras. Como uma estratégia de defesa, as pessoas negras tentam ocultar ou disfarçar alguns traços da sua africanidade, visto que a identidade nacional foi forjada pelo ideário socialmente construído do branqueamento social (Santana \& Santos, 2016; Silva, 2017). Dessa forma, como fora demonstrado a partir da composição da classe 2 , a representatividade negra funciona como um expoente positivo no combate ao racismo cordial.

Assumir a identidade negra no Brasil pode ser um processo muito doloroso, dado que se tem como padrão positivo a cor branca. A construção desse padrão foi realizada a partir de um discurso impreciso da mestiçagem, onde inicialmente tentou-se atestar uma inferioridade aos negros e posteriormente a miscigenação foi exaltada a partir de características 
europeias (Malafaia, 2018). Essa construção fez com que diversos termos fossem criados para se referir a uma pessoa negra, como moreno, marrom bombom, moreno cor de canela ou termos parecidos, dando a impressão de que chamar alguém de negro indicasse ofensa (Malafaia, 2018).

O processo de identificação é de suma importância para a constituição e transformação do sujeito. Sendo assim, é necessário que haja um modelo inspirador para provocar reconhecimento por parte dos indivíduos e um movimento de subversão da negatividade da identidade negra (Souza, 1983). Para que isso ocorra se faz necessário a elaboração da identidade negra de forma positiva, a partir da afirmação de suas características e do reconhecimento da luta e da historicidade negra no país (Gomes, 2012).

$\mathrm{Na}$ atualidade impera um discurso onde o brasileiro se reconhece enquanto desprovido de qualquer tipo de preconceito ou racismo, essa lógica vem do mito da democracia racial. Esse mito constituiu-se a partir de uma crença de que após a abolição da escravidão no Brasil o negro passaria a desfrutar de todos os direitos disponíveis, entraria em vigor uma democracia racial. Entretanto, o que ocorreu e, infelizmente se perpetua na atualidade, é uma desigualdade nas relações raciais (Domingues, 2006). Essas relações desiguais podem ser apreendidas a partir da observação da constituição da classe 3 , em que se percebe a desigualdade, mas nada é de responsabilidade do próprio sujeito.

Assim, na medida em que a valorização de aspectos constituintes da identidade de uma população é instaurada a partir da presença ativa de determinados atores sociais, observouse uma relação mais direta entre a classe 2 e a classe 4 . A representatividade negra pode funcionar como um dispositivo de anulação da dinâmica de inferiorização social da população negra. Em decorrência da inferiorização do negro historicamente constituída e socialmente sustentada pela sociedade brasileira, a restrição de acesso a novas oportunidades desse grupo social específico tornou-se rotineira.

Nessa perspectiva Turra e Venturi (1995) apontam a classe social como um dos pressupostos do racismo no Brasil, o racismo explícito nos comentários da classe 4 inferioriza o negro como aquele que não é capaz de se inserir no mercado de trabalho ou ensino superior. O posicionamento desta crença é vivenciado nas práticas sociais, onde o negro ainda é frequentemente tomado como aquele que deve realizar trabalhos braçais (Pacheco, 2011). 


\section{CONCLUSÕES}

Considerando os aspectos destacados nos resultados, fica evidente que a intolerância racial no país é constantemente expressa por meio de comentários em redes sociais, mais especificamente através do Facebook e de sua popularização. Dessa forma, a análise realizada demonstrou que assim como apresentado por Turra e Venturi (1995), o racismo no Brasil é marcado pelo paradigma da cordialidade. A trajetória histórica da sociedade brasileira referente aos negros foi construída pelo viés da dominação e subordinação, aspectos que repercutem nas relações sociais da sociedade contemporânea.

No Brasil, a sociedade impõe o branqueamento como paradigma de formas de subjetivação. Desta forma, a partir da negação de sua historicidade, encontra-se a anulação de características próprias da cultura negra. A tentativa de inferiorizar esta população a partir de atitudes permeadas por um racismo velado, disfarçado na utopia da democracia racial funciona enquanto um mecanismo de regulação. São essas ideias que sustentam a manutenção da discriminação racial, visto que essa crença é oriunda de uma cultura que inferioriza o negro, na qual há uma constante opressão do diferente, atitude congruente com o comportamento intolerante explicitado no Facebook.

Com relação aos resultados do presente estudo, é possível observar a presença de crenças racistas no Facebook, cujos elementos constituintes estão apoiados em atitudes algumas vezes polidas, mas sempre caracterizadas por atitudes preconceituosas. Estes dados confirmam que o racismo ainda permanece no ideário nacional, em decorrência não somente dos comentários expostos nas redes sociais, como também, a partir do posicionamento agressivo que perdura no cotidiano, observa-se como o racismo é um construto multifacetado e, portanto, precisa ser alvo de múltiplas reflexões. No entanto, vale destacar que essa não é uma problemática exclusiva do Brasil.

É preciso elaborar as discussões acerca do racismo a partir de uma esfera política, psicossocial e cultural, que considere sua complexidade e variabilidade. Por fim, embora os objetivos tenham sido alcançados, é importante salientar que há algumas limitações. Vale ressaltar a especificidade do corpus textual utilizado neste estudo, fato que demonstra a impossibilidade da realização de generalizações para todo o espaço virtual nacional. Nessa perspectiva, uma vez que estudos dessa natureza são essenciais para preencher lacunas na literatura da área, espera-se que estudos posteriores sejam elaborados a partir dos resultados obtidos nesta oportunidade. Por isso, seria fundamental anexar outros estudos 
cujos corpus textuais sejam mais diversificados, contemplando outras redes sociais que estão presentes no cotidiano dos internautas brasileiros, como por exemplo o Instagram e o

Twitter.

\section{REFERÊNCIAS}

Afonso, A. (2010). Manual de Tecnologias da Informação e Comunicação e OpenOffice.org. Disponível em http://www.adrianoafonso.net/files/manuais/manual_tic_2ed_nivelbase_anjaf.pdf

Allport, G. W. (1954). The nature of prejudice. Cambridge: Addison-Wesley.

Bernardino, J. (2002). Ação afirmativa e a rediscussão do mito da democracia racial no Brasil. Estudos AfroAsiáticos, 24(2), 247-273.

Camargo, B. V., \& Justo, A. M. (2013). IRAMUTEQ: Um software gratuito para análise de dados textuais. Temas em Psicologia, 21, 513-518.

Camargo, B. V., \& Justo, A. M. (2016). Tutorial para uso do software IRAMUTEQ. Disponível em http://www.iramuteq.org/documentation/fichiers/Tutorial\%20IRaMuTeQ\%20em\%20portugues_17.03.2016.p df

Cruz, A. M. (2017). História e cultura afro-brasileira: uma análise da implementação da Lei 10.639/03 no Colégio Cataratas do Iguaçu. UNILA.

Domingues, P. (2005). O mito da democracia racial e a mestiçagem no Brasil (1889-1930). Diálogos Latinoamericanos, 5(10), 117-131.

Fernandes, S. C. S. (2011). Crenças Raciais e Infra-humanização: uma análise psicossocial do preconceito contra negros. Universidade Federal da Bahia.

Folha de São Paulo (2013). Brasil chega a 76 milhões de usuários no Facebook; mais da metade acessa do celular. F5- Humanos. Disponivel em http://www1.folha.uol.com.br/fsp/mercado/124085-usuarios-dofacebook-sao-76-mi-no-pais.shtml

França, D. X., \& Monteiro, M. B. (2015). Identidade racial e preferência em crianças brasileiras de cinco a dez anos. Psicologia, 16(2), 293-323.

Gomes, N. L. (2012). Movimento negro e educação: ressignificando e politizando a raça. Educação \& Sociedade, 33(120), 727-744.

Guimarães, A. S. A. (2004). Preconceito de cor e racismo no Brasil. Revista de Antropologia, São Paulo, 47(1), 9-43.

Kemp, S. Special Reports Digital In 2018: world's internet users pass the 4 billion mark. [S. I.]. Disponível em https://wearesocial.com/blog/2018/01/global-digital-report-2018.

Kleina, M. C. N. (2016). Curtir, Comentar ou Compartilhar? As Potencialidades do Facebook Como Ferramenta de Mobilização Digital. Em Debate, Belo Horizonte, 8(4), 33-40.

Malafaia, E. D. S. (2018). A importância da representatividade negra na construção de identificação em crianças negras a partir de literatura infanto-juvenil negra. X COPENE: Congresso Brasileiro de Pesquisadores Negros. Uberlândia - MG.

Martins, A. C. L.(2019). Discurso de ódio em redes sociais e reconhecimento do outro: o caso M. Revista Direito GV, São Paulo, 15(1), 1-30.

Myers, D. G. (2014). Psicologia Social: AMGH Editora. 
Pacheco, L. C. (2011). Racismo cordial: manifestação da descriminalização racial à brasileira - o domínio público e privado. Revista de Psicologia, Fortaleza, 2(1), 137-144.

Pires, A. M. L. T. (2010). El prejuicio racial en Brasil: medidas comparativas. Psicologia Social, Florianópolis, 22(1), 32-42.

Ratinaud, P. (2009). IRAMUTEQ: Interface de R pour les Analyses Multidimensionnelles de Textes et de Questionnaires [Computer software]. Disponível em http://www.iramuteq.org

Salviati, E. M. (2017). Manual do Aplicativo Iramuteq. Planaltina, DF.

Santana, N. M. C.; Santos, R. A. (2016). Projetos de modernidade: autoritarismo, eugenia e racismo no Brasil do século XX. Revista de Estudios Sociales, (58), 28-38.

Silva, T. M. G. S. (2017). O colorismo e suas bases históricas discriminatórias. Direito UNIFACS-Debate Virtual, (201), 1-19.

Silva, A. C. (2019). Vítima de racismo de brasileiros, jogadora francesa superou "fim do mundo". Paris, 25 jun. 2019. Disponível em https://esporte.uol.com.br/futebol/ultimas-noticias/2019/06/25/vitima-de-racismo-debrasileiros-atleta-francesa-ja-venceu-fim-do-mundo.htm.

Silva, M. L. (2017) População-sacer e democracia racial no Brasil. Sociedade e Estado, 32(3), 593-620.

Souza, N. S. (1983). Tornar-se Negro: as vicissitudes da identidade do negro brasileiro em ascensão social. $2^{\mathrm{a}}$ edição. Rio de Janeiro. Editora graal.

Stein, M., Nodari, C. H. \& Salvagni, J. (2018). Disseminação do ódio nas mídias sociais: análise da atuação do social media. Interações, Campo Grande, 19(1), 43-59.

Turra, C. \& Venturi, G. (1995). Racismo cordial: a mais completa análise de preconceito de cor no Brasil. São Paulo: Ática. 